\title{
Smoking and comorbidities are associated with COVID-19 severity and mortality in 565 patients treated in Turkey: a retrospective observational study
}

1. Assistant Professor, Department of Pulmonology, Sultan 2.Abdulhamit Han Training and Research Hospital, Health Sciences University, Istanbul, Turkey. 2. Pulmonologist, Department of Pulmonology, Sultan 2.Abdulhamit Han Training and Research Hospital, Health Sciences University, Istanbul, Turkey.

http://dx.doi.org/10.1590/1806-9282.66.12.1679

\section{SUMMARY}

OBJECTIVE: We aimed to explore the prevalence of smoking rates and comorbidities and evaluate the relationship between them and disease severity and mortality in inpatients with COVID-19.

METHODS: COVID-19 patients were divided into the following groups: clinic group, intensive care unit (ICU) group, survivors, and non-survivors. Non-COVID-19 patients were included as a control group. The groups were compared.

RESULTS: There was no difference between patients with and without COVID-19 in terms of smoking, asthma, diabetes, dementia, coronary artery disease (CAD), hypertension, chronic renal failure and arrhythmia ( $p>0.05)$. Older age (Odds ratio (OR), 1.061; 95\% confidence interval (Cl): 1.041-1.082; $p<0.0001)$, chronic obstructive pulmonary disease (COPD) $(\mathrm{OR}, 2.775 ; 95 \%$ Cl: 1.128-6.829; $p=0.026)$ and $\operatorname{CAD}(O R, 2.696 ; 95 \% \mathrm{Cl}$ : 1.216-5.974; $p=0.015)$ were significantly associated with ICU admission. Current smoking (OR, 5.101; 95\% Cl: 2.382-10.927; $p<0.0001)$ and former smoking (OR, 3.789; 95\% Cl: 1.845-7.780; $p<0.0001)$ were risk factors for ICU admission. Older age (OR; 1.082; 95\% Cl: 1.056-1.109; $p<0.0001)$, COPD (OR, 3.213; 95\% Cl: 1.224-8.431; p=0.018), CAD (OR, 6.252; 95\% Cl: 2.171-18.004; $p=0.001)$ and congestive heart failure (CHF) (OR, 5.917; 95\% Cl 1.069-32.258; $p=0.042)$, were significantly associated with mortality. Current smoking (OR, 13.014; 95\% Cl: 5.058-33.480; $p<0.0001)$ and former smoking (OR, 6.507; 95\% Cl 2.731-15.501; p<0.0001) were also risk factors for mortality.

CONCLUSION: Smoking, older age, COPD, and CAD were risk factors for ICU admission and mortality in patients with COVID-19. CHF was not a risk factor for ICU admission; however, it was a risk factor for mortality.

KEYWORDS: Smoking, Mortality, COVID-19, Comorbidity, Severity

\section{INTRODUCTION}

The COVID-19 pandemic, caused by SARS-CoV-2 is still ongoing and has caused hundreds of thousands of deaths worldwide. The lack of currently approved treatment and vaccination makes it difficult to fight against the disease. Identifying and understanding the risk factors for mortality and poor prognosis of the disease will determine the clinical approach and treatments to be applied to patients.

In 2019, around a fourth (24.9\%) of the global population (both sexes combined) aged 15 years and older

DATE OF SUBMISSION: 02-Sep-2020

DATE OF ACCEPTANCE: 02-Sep-2020

CORRESPONDING AUTHOR: Tayfun Caliskan

Department of Pulmonology, Sultan 2. Abdulhamit Han Training and Research Hospital, Health Sciences University

Tibbiye Avenue, Selimiye Street, Uskudar, Istanbul, Turkey - 34688

Tel: +90 021 6542-2020

E-mail: drtcaliskan@yahoo.com 
were current users of some form of tobacco, and more than 8 million people died from tobacco use including both tobacco smoking and smokeless tobacco use in 2017. ${ }^{1}$ Active smoking has been reported to increase the risk of viral respiratory diseases. ${ }^{2}$ Smokers have an increased risk for community-acquired pneumonia. $^{3}$ About $20 \%$ of COVID-19 patients develop pulmonary infiltrates and some of these will develop very severe disease, hypoxia, and progression to ARDS. ${ }^{4}$ The angiotensin-converting enzyme (ACE-2) protein, which is expressed on the surface of lung type-2 pneumocytes, is an entry receptor for SARS-CoV-2. ${ }^{4}$ ACE-2 gene expression and is higher in smokers than in non-smokers, which may explain the increased risk of severe COVID-19 in this population. ${ }^{5}$ On the other hand, Lippi et al. reported that smoking was not associated with COVID-19 severity. ${ }^{6}$

Comorbidities were associated with the severity of COVID-19. ${ }^{7}$ The fatality rate also increased in patients with comorbidities. ${ }^{8}$ Older age, male sex, and comorbidities including chronic cardiac disease, non-asthmatic chronic pulmonary disease, chronic kidney disease, liver disease, and obesity were associated with higher in-hospital mortality. ${ }^{9}$ There are conflicting results in studies for the prevalence of comorbidities and the factors affecting COVID-19 severity and mortality. The interpretation of the effects of smoking on COVID-19 is difficult, because one of the factors affecting smoking status is gender, and cardiovascular diseases are more common in smokers. Combined hormonal contraception with other risk factors increases venous thromboembolism risk, especially in patients hospitalized with COVID-19. ${ }^{10}$ Menopausal hormone therapy also affects the risk of cardiovascular diseases. ${ }^{11}$

We aimed to explore the prevalence of smoking rates and comorbidities and evaluate the relationship between smoking and comorbidities with disease severity and mortality in inpatients with and without COVID-19 in this study.

\section{METHODS}

This retrospective observational study was conducted in Sultan 2, in the Abdulhamit Han Training\& Research Hospital, which has also been a COVID-19 reference center during the pandemic, in Istanbul, Turkey, between March 15 and May 10, 2020. The study was approved by the local ethics committee (179/May 12, 2020). Adult patients ( $\geq 18$ years old) diagnosed with COVID-19 by polymerase chain reaction (PCR) and whose COVID-19 diagnosis was based on clinical, laboratory, and radiological findings, especially with chest computed tomography findings, despite COVID-19 PCR negativity were included. Non-COVID-19 patients who were hospitalized in the department of pulmonology due to diseases other than COVID-19 were included as the control group. The data were extracted from electronic medical records of the hospital. Age, smoking status, comorbidities including hypertension, coronary artery disease (CAD), arrhythmia, congestive heart failure (CHF), diabetes, chronic obstructive pulmonary disease (COPD), asthma, dementia, and chronic renal failure (CRF) were recorded based on patients' self-reporting or information received from patient relatives. The smoking status was classified as current smoker, former smoker, and never smoked. Former smokers were patients who reported having smoked $\geq 100$ cigarettes during their lifetime and were not smoking for at least the past three months. The patients with COVID-19 were divided into two groups: a clinic group and an intensive care unit (ICU) group. In addition, the patients were divided into two groups: survivors and non-survivors. The groups were compared in terms of smoking, age, and comorbidities.

Patient data collected in the study were analyzed with the IBM Statistical Package for the Social Sciences (SPSS) for Windows 21.0 package program (Statistical Package for the Social Sciences, Chicago, IL, USA). Discrete data is given as frequency and percentage. The mean \pm standard deviation for continuous data is given as descriptive value. The Mann Whitney U-test was used to compare the two groups. The Pearson Chi-Square Test and Fisher's Exact Test were used to compare the two categorical groups. Logistic Regression Analysis was used to examine the risk factors for mortality and intensive care unit admission. The results were considered statistically significant when the p-value was less than 0.05 .

\section{RESULTS}

The study included 565 patients hospitalized with COVID-19 and 248 patients hospitalized with nonCOVID-19 diseases. The mean ages of the patients with and without COVID-19 were $48.0 \pm 19.7$ and $52.0 \pm$ 21.1 (Table 1). There was no statistically significant difference between patients with and without COVID19 in terms of smoking, asthma, diabetes, dementia, 
CAD, hypertension, CRF, and arrhythmia ( $p>0.05)$. Non-COVID-19 patients were older than COVID19 patients $(p=0.014)$. COPD and CHF were more common in non-COVID-19 patients than in patients with COVID-19 (18.9\%, $9.6 \%$ vs. $6.5 \%, 2.5 \%$, $\mathrm{p}<0.001)$. Hypertension (22.7\%), diabetes (12.7\%), CAD (7.4\%) and COPD (6.5\%), were the most common comorbidities in patients with COVID-19. The ICU group had a significantly higher proportion of patients with current and former smoking than the clinic group $(24.2 \%, 37.4 \%$, vs. $20.3 \%, 9.5 \%, \mathrm{p}<0.0001$ ) (Table 2). The patients in the ICU group were significantly older than those in the clinic group ( $p<0.0001)$. COPD, diabetes, dementia, CAD, hypertension, CRF, and arrhythmia were found to be significantly more common in the ICU group than in the clinic group $(p<0.05)$. There was no difference between the two groups for asthma and CHF ( $p>0.05)$. The results of the logistic regression analysis demonstrated that older age [Odds ratio (OR), 1.061; 95\% confidence interval (CI): 1.041-1.082; $\mathrm{p}<$ 0.0001], COPD (OR, 2.775; 95\% CI: 1.128-6.829; $\mathrm{p}=$ 0.026), and CAD (OR, 2.696; 95\% CI: 1.216-5.974; $p=$ 0.015) were significantly associated with ICU admission (Table 3). Current smoking (OR, 5.101; 95\% CI: 2.382-10.927; $\mathrm{p}<0.0001$ ) and former smoking (OR, 3.789; 95\% CI: $1.845-7.780 ; \mathrm{p}<0.0001)$ were risk factors for ICU admission. Diabetes, dementia, hypertension, CRF, and arrhythmia were not significantly associated with ICU admission.

Non-survivors were older than survivors $(p<0.0001)$ (Table 2). Current smokers and former smokers were more common in non-survivors $(\mathrm{p}<0.0001)$. COPD,

TABLE 1. COMPARISON BETWEEN PATIENTS WITH AND WITHOUT COVID-19

\begin{tabular}{l|l|l|l} 
& $\begin{array}{l}\text { COVID-19 }(\mathrm{N}=565) \\
\mathrm{N}(\%)\end{array}$ & $\begin{array}{l}\text { Non-COVID-19 (N=248) } \\
\text { N }(\%)\end{array}$ & $P$ \\
\hline Age, median (IQR) & $48 \pm 19.664$ & $52 \pm 21.105$ & 0.014 \\
\hline Current smoker & $118(20.9)$ & $47(18.9)$ & 0.738 \\
\hline Former smoker & $79(14.0)$ & $33(13.3)$ & \\
\hline Never smoked & $368(65.1)$ & $169(67.9)$ & $<0.0001$ \\
\hline COPD & $37(6.5)$ & $47(18.9)$ & 0.839 \\
\hline Asthma & $21(3.7)$ & $8(3.2)$ & 0.186 \\
\hline Diabetes & $72(12.7)$ & $41(16.5)$ & 0.572 \\
\hline Dementia & $12(2.1)$ & $3(1.2)$ & 0.124 \\
\hline CAD & $42(7.4)$ & $11(4.4)$ & 0.715 \\
\hline Hypertension & $128(22.7)$ & $53(21.3)$ & 0.234 \\
\hline Chronic renal failure & $12(2.1)$ & $9(3.6)$ & $<0.0001$ \\
\hline CHF & $14(2.5)$ & $24(9.6)$ & 0.639 \\
\hline
\end{tabular}

IQR: interquartile range; COPD: Chronic pulmonary obstructive disease; CAD: Coronary artery disease; CHF: Congestive heart failure.

TABLE 2. SMOKING STATUS AND COMORBIDITIES OF THE PATIENTS WITH COVID-19

\begin{tabular}{|c|c|c|c|c|c|c|}
\hline & $\begin{array}{l}\text { Clinic (N=474) } \\
\mathrm{N}(\%)\end{array}$ & $\begin{array}{l}\operatorname{ICU}(\mathrm{N}=91) \\
\mathrm{N}(\%)\end{array}$ & $\mathrm{p}$ & $\begin{array}{l}\text { Survivors }(N=490) \\
N(\%)\end{array}$ & $\begin{array}{l}\text { Non-survivors }(\mathrm{N}=75) \\
\mathrm{N}(\%)\end{array}$ & $\mathrm{p}$ \\
\hline Current smoker & $96(20.3)$ & $22(24.2)$ & \multirow[t]{3}{*}{$<0.0001$} & $97(19.8)$ & $21(28.0)$ & \multirow[t]{3}{*}{$<0.0001$} \\
\hline Former smoker & $45(9.5)$ & $34(37.4)$ & & $48(9.8)$ & $31(41.3)$ & \\
\hline Never smoked & $333(70.3)$ & $35(38.5)$ & & $345(70.4)$ & $23(30.7)$ & \\
\hline Age, median (IQR) & $44(26-57)$ & $69(58-79)$ & $<0.0001$ & $44(27-57)$ & $70(62-80)$ & $<0.0001$ \\
\hline COPD & $12(2.5)$ & $25(27.5)$ & $<0.0001$ & $12(2.4)$ & $25(33.3)$ & $<0.0001$ \\
\hline Asthma & $17(3.6)$ & $4(4.4)$ & 0.761 & $17(3.5)$ & $4(5.3)$ & 0.506 \\
\hline Diabetes & $49(10.3)$ & $23(25.3)$ & $<0.0001$ & $54(11.0)$ & $18(24.0)$ & 0.004 \\
\hline Dementia & $7(1.5)$ & $5(5.5)$ & 0.030 & $7(1.4)$ & $5(6.7)$ & 0.013 \\
\hline CAD & $22(4.6)$ & $20(22.0)$ & $<0.0001$ & $24(4.9)$ & $18(24.0)$ & $<0.0001$ \\
\hline Hypertension & $81(17.1)$ & $47(51.6)$ & $<0.0001$ & $88(18.0)$ & $40(53.3)$ & $<0.0001$ \\
\hline Chronic renal failure & $6(1.3)$ & $6(6.6)$ & 0.006 & $7(1.4)$ & $5(6.7)$ & 0.013 \\
\hline $\mathrm{CHF}$ & $9(1.9)$ & $5(5.5)$ & 0.059 & $9(1.8)$ & $5(6.7)$ & 0.027 \\
\hline Arrhythmia & $8(1.7)$ & $6(6.6)$ & 0.015 & $8(1.6)$ & $6(8.0)$ & 0.006 \\
\hline
\end{tabular}

ICU: Intensive care unit; IQR: interquartile range; COPD: Chronic pulmonary obstructive disease; CAD: Coronary artery disease; CHF: Congestive heart failure. 
diabetes, dementia, CAD, hypertension, $\mathrm{CRF}, \mathrm{CHF}$, and arrhythmia were significantly more common among non-survivors than in survivors $(\mathrm{p}<0.05)$. There was no difference between non-survivors and survivors in terms of asthma ( $p>0.05)$. The logistic regression analysis indicated that older age (OR; $1.082 ; 95 \%$ CI: 1.056-1.109; $\mathrm{p}<0.0001)$, COPD (OR, 3.213; 95\% CI: $1.224-8.431 ; \mathrm{p}=0.018)$, CAD (OR, 6.252; 95\% CI: 2.171 $18.004 ; \mathrm{p}=0.001)$, and CHF (OR, 5.917; 95\% CI 1.069$32.258 ; p=0.042)$, were significantly associated with mortality (Table 3). Current smoking (OR, 13.014; 95\% CI: 5.058-33.480; $\mathrm{p}<0.0001)$ and former smoking (OR, 6.507; 95\% CI 2.731-15.501; $\mathrm{p}<0.0001)$ were risk factors for mortality. Diabetes, dementia, hypertension, CHF, and arrhythmia were not significantly associated with mortality $(p>0.05)$.

\section{DISCUSSION}

In this study, the prevalence of comorbidities and the factors affecting COVID-19 prognosis were examined. Revealing these risk factors can be decisive and guide clinicians towards the effective treatment and proper management of patients with COVID-19.

There was no difference in smoking between COVID-19 and non-COVID-19 patients. The rate of active smokers and former smokers were significantly higher among patients who were admitted to the ICU. Current smoking was associated with 5 -fold and 13-fold increased risks respectively for ICU admission and mortality in the present study. Former smokers were 3.7 times more likely to be admitted to ICU and 6.5 times more likely to die than non-smokers.
Lippi et al. reported that smoking did not affect the severity of COVID-19. ${ }^{6}$ However, active cigarette smoking was associated with the risk of severe COVID-19 in the re-analysis of the data. ${ }^{12}$ In studies conducted in COVID-19 patients in China, smoking rates were lower than among the general population. ${ }^{13}$ This may be related to the inability to receive patient data, record data, and health system deficiencies during the pandemic. In the study by Zhou F et al., there was no difference between patients who recovered and died in terms of active smoking ( $4 \%$ vs. $9 \% \mathrm{p}=0.21){ }^{14}$ Conversely, Guan W et al. indicated that the smoking rate was higher in patients with severe COVID-19 patients. ${ }^{15}$

COPD was more common in non-COVID-19 patients than in COVID-19 patients, but this was due to the fact that patients were hospitalized in the department of pulmonology. In a meta-analysis, patients with COPD had a 5-fold increased risk of severe COVID$19 .{ }^{16}$ Patients with COPD have also a higher risk for in-hospital mortality due to COVID-19. ${ }^{17}$ The results of the present study were compatible with previous reports, and COPD was a risk factor for ICU admission and mortality. The increased risk for severe COVID-19 in patients with asthma has not been proven in studies yet. The prevalence of asthma in COVID-19 patients in China was lower than in the general population. ${ }^{18}$ Asthma was not a risk factor for ICU admission and mortality in the present study.

Hypertension was reported to be associated with a 2.5-fold increased risk for COVID-19 severity and mortality, especially in the elderly. ${ }^{19}$ The mortality risk of hypertensive COVID-19 patients was increased, with

TABLE 3. MULTIVARIATE LOGISTIC REGRESSION ANALYSIS OF VARIABLES RELATED TO ICU ADMISSION AND MORTALITY

\begin{tabular}{l|l|l|l|l} 
Risk factor & \multicolumn{2}{|c|}{ For ICU admission } & \multicolumn{2}{c}{ For mortality } \\
\hline & OR $(\% 95 \mathrm{CI})$ & P-value & OR $(\% 95 \mathrm{CI})$ & P-value \\
\hline Former smoker & $3.789(1.845-7.780)$ & $<0.0001$ & $6.507(2.731-15.501)$ & $<0.0001$ \\
\hline Current smoker & $5.101(2.382-10.927)$ & $<0.0001$ & $13.014(5.058-33.480)$ & $<0.0001$ \\
\hline Age & $1.061(1.041-1.082)$ & $<0.0001$ & $1.082(1.056-1.109)$ & $<0.0001$ \\
\hline COPD & $2.775(1.128-6.829)$ & 0.026 & $3.213(1.224-8.431)$ & 0.018 \\
\hline Diabetes & $1.152(0.553-2.396)$ & 0.706 & $1.037(0.445-2.421)$ & 0.932 \\
\hline Dementia & $1.249(0.315-4.952)$ & 0.751 & $1.762(0.408-7.607)$ & 0.448 \\
\hline CAD & $2.696(1.216-5.974)$ & 0.015 & $6.252(2.171-18.004)$ & 0.001 \\
\hline Hypertension & $1.571(0.818-3.016)$ & 0.175 & $1.458(0.690-3.079)$ & 0.323 \\
\hline Chronic renal failure & $3.685(0.983-13.811)$ & 0.053 & $3.982(0.939-16.891)$ & 0.061 \\
\hline CHF & NA & NA & $5.917(1.069-32.258)$ & 0.042 \\
\hline Arrhythmia & $1.649(0.446-6.097)$ & 0.453 & $2.804(0.689-11.412)$ & 0.150 \\
\hline
\end{tabular}

ICU: Intensive care unit; OR: Odds ratio; Cl: Confidence interval; COPD: Chronic pulmonary obstructive disease; CAD: Coronary artery disease; CHF: Congestive heart failure; NA: Not applicable. 
an OR of $3.36 .^{20}$ Although hypertension was the most common comorbidity in the present study, it was not a risk factor for ICU admission and mortality. According to this study, arrhythmia was not a risk factor for ICU admission and mortality. CAD was a risk factor for both ICU admission and mortality, and CHF was not a risk factor for ICU admission but was a risk factor for mortality in the present study. Non-COVID-19 patients were older patients who needed inpatient treatment; therefore CHF was more common in non-COVID-19 patients than in COVID-19 patients. Cardiac injury was a common comorbidity in COVID-19 patients treated in a hospital in Wuhan and increased mortality. ${ }^{21}$ ACE-2 levels were higher in patients with cardiovascular disease. $^{22}$ On the other hand, SARS-CoV-2 can reduce ACE-2, causing excessive accumulation of angiotensin II, which induces myocarditis and acute respiratory distress syndrome. ${ }^{22}$

In a previous study, diabetes was associated with COVID-19 severity and mortality, and this was particularly evident in younger and less hypertensive patients. ${ }^{23}$ Diabetes was the second most common comorbidity in the present study but it was not a risk factor for ICU admission and mortality. CRF has been associated with an increased risk of severe COVID19. ${ }^{24}$ Another study concluded that renal disease did not increase the risk of COVID-19. ${ }^{25} \mathrm{CRF}$ was not a risk factor for ICU admission and mortality in this study. Patients with Alzheimer's disease and related dementias have an increased risk of COVID-19. ${ }^{26}$ Therefore, concerns have arisen regarding these patients during the COVID-19 pandemic. Dementia was not a risk factor for ICU admission and mortality in the present study. It has been reported that in-hospital mortality was higher in patients over 65 years old with COVID$19 .{ }^{17}$ Older age was also a risk factor for ICU admission and mortality in the present study.
The most important limitation of this study was its retrospective design. Therefore, data about patients' medical records in the hospital system were used. Comorbidities were also checked from the e-pulse system to prevent a lack of data. Missing data about smoking status was completed by contacting the patient or relatives by phone.

\section{CONCLUSION}

Smoking, older age, COPD, and CAD were risk factors for ICU admission and mortality in inpatients treated for COVID-19. Asthma, diabetes, dementia, hypertension, CRF, and arrhythmia were not associated with ICU admission and mortality. CHF was not a risk factor for ICU admission; however, it was a risk factor for mortality.

\section{Sources of funding}

The authors received no financial support for the research and/or authorship of this article.

\section{Conflict of interest}

The authors declare that they have no conflict of interest.

\section{Ethics}

Informed consent was waived because of the retrospective nature of the study. This study was approved by the Ethics Committee of the Umraniye Training and Research Hospital (No: 179, Date: May 12, 2020).

\section{Author's Contribution}

TC, BS designed the study; BS collected the data; TC performed the literature review; BS performed the statistical analysis; TC wrote the paper; TC, BS performed the critical review of the manuscript.

\section{RESUMO}

OBJETIVO: Buscamos explorar as taxas de prevalência de tabagismo e de comorbidades e avaliar a relação entre elas e a severidade e mortalidade da doença em pacientes hospitalizados com COVID-19.

MÉTODOS: Pacientes com COVID-19 foram divididos nos seguintes grupos: grupo clínico, grupo da unidade de terapia intensiva (UTI), grupo de sobreviventes e não-sobreviventes. Pacientes sem COVID-19 foram incluídos em um grupo de controle. Os grupos foram comparados.

RESULTADOS: Não houve diferença entre os pacientes com e sem COVID-19 em termos de tabagismo, asma, diabetes, demência, doença arterial coronariana (DAC), hipertensão arterial, insuficiência renal crônica e arritmia ( $p>0,05$ ). Idade mais avançada (odds ratio $(O R), 1,061 ; 95 \%$ de intervalo de confiança (IC): 1,041-1,082; $p<0,0001)$, doença pulmonar obstrutiva crônica (DPOC) (OR, 2,775; 95\% IC: 1,128-6,829; $p=0,026)$ e DAC (OR, 2,696; 95\% IC: 1,216-5,974; $p=0,015)$ estavam significativamente associados com a admissão na UTI. O tabagismo atual (OR, 5,101; 95\% IC: 2,382-10,927; $p$ < 0,0001) e tabagismo prévio (OR, 3,789; 95\% IC: 1,845-7,780; $p<0,0001)$ 
foram fatores de risco para admissão na UTI. Idade mais avançada (OR; 1,082; 95\% IC: 1,056-1,109; < 0,0001), DPOC (OR, 3,213; 95\% IC: 1,224-8,431; $p=0,018)$, DAC (OR, 6,252; 95\% IC: 2,171-18,004; $p=0,001)$ e insuficiência cardíaca congestiva (ICC) (OR, 5,917; 95\% IC 1,069-32,258; $p=0,042)$ estavam significativamente associados com mortalidade. O tabagismo atual (OR, 13,014; 95\% IC:5,058-33,480; $p<0,0001)$ e o tabagismo prévio (OR, 6,507; 95\% IC 2,731-15,501; $p<0,0001)$ também foram fatores de risco para mortalidade.

CONCLUSÃO: O tabagismo, a idade avançada, DPOC e DAC foram fatores de risco para admissão na UTI e mortalidade em pacientes com COVID-19. ICC não foi um fator de risco para admissão na UTI; no entanto, foi um fator de risco para mortalidade.

PALAVRAS-CHAVE: Tabagismo, Mortalidade, COVID-19, Comorbidade, Gravidade

\section{REFERENCES}

1. WHO global report on trends in prevalence of tobacco use 2000-2025, third edition. Geneva: World Health Organization: 2019.

2. Lawrence $H$, Hunter A, Murray R, Lim WS, McKeever T. Cigarette smoking and the occurrence of influenza - Systematic review. J Infect. 2019;79(5):401-6.

3. Baskaran V, Murray RL, Hunter A, Lim WS, McKeever TM. Effect of tobacco smoking on the risk of developing community acquired pneumonia: A systematic review and meta-analysis. PLoS One. 2019;14(7):e0220204.

4. Mason RJ. Pathogenesis of COVID-19 from a cell biology perspective. Eur Respir J. 2020;55(4):2000607.

5. Cai G, Bossé Y, Xiao F, Kheradmand F, Amos Cl. Tobacco Smoking Increases the Lung Gene Expression of ACE2, the Receptor of SARS-CoV-2. Am I Respir Crit Care Med. 2020;201(12):1557-9.

6. Lippi G, Henry BM. Active smoking is not associated with severity of coronavirus disease 2019 (COVID-19). Eur J Intern Med. 2020;75:107-8.

7. Yang J, Zheng Y, Gou X, Pu K, Chen Z, Guo Q, et al. Prevalence of comorbidities and its effects in patients infected with SARS-CoV-2: a systematic review and meta-analysis. Int ] Infect Dis. 2020;94:91-5.

8. Wu Z, McGoogan JM. Characteristics of and Important Lessons From the Coronavirus Disease 2019 (COVID-19) Outbreak in China: Summary of a Report of 72314 Cases From the Chinese Center for Disease Control and Prevention. JAMA. 2020;10.1001/jama.2020.2648.

9. Docherty $A B$, Harrison EM, Green CA, Hardwick HE, Pius R, Norman L, et al. Features of 20133 UK patients in hospital with COVID-19 using the ISARIC WHO Clinical Characterisation Protocol: prospective observational cohort study. BMJ. 2020;369:m1985.

10. Carbonel AAF, Simões RS, Girão MJBC, Soares Júnior JM, Baracat EC. Cardiovascular system and estrogen in menopause. Rev Assoc Med Bras (1992). 2020;66(2):97-8.

11. Ferreira-Filho ES, de Melo NR, Sorpreso ICE, Bahamondes L, Simões RDS, Soares Júnior JM, Baracat EC. Contraception and reproductive planning during the COVID-19 pandemic. Expert Rev Clin Pharmacol. 2020;13(6):615-22

12. Guo FR. Active smoking is associated with severity of coronavirus disease 2019 (COVID-19): An update of a meta-analysis. Tob Induc Dis. 2020;18:37.

13. Farsalinos K, Barbouni A, Niaura R. Systematic review of the prevalence of current smoking among hospitalized COVID-19 patients in China: could nicotine be a therapeutic option? Intern Emerg Med. 2020;15(5):845-52.

14. Zhou F, Yu T, Du R, Fan G, Liu Y, Liu Z, et al. Clinical course and risk factors for mortality of adult inpatients with COVID-19 in Wuhan, China: a retrospective cohort study. Lancet. 2020;395(10229):1054-62.

15. Guan WJ, Ni ZY, Hu Y, Liang WH, Ou CQ, He JX, et al. Clinical Characteristics of Coronavirus Disease 2019 in China. N Engl J Med. 2020;382(18):1708-20.

16. Lippi G, Henry BM. Chronic obstructive pulmonary disease is associated with severe coronavirus disease 2019 (COVID-19). Respir Med. 2020;167:105941.

17. Alqahtani IS, Oyelade T, Aldhahir AM, Alghamdi SM, Almehmadi M, Alqahtani AS, et al. Prevalence, Severity and Mortality associated with COPD and Smoking in patients with COVID-19: A Rapid Systematic Review and Meta-Analysis. PLoS One. 2020;15(5):e0233147.

18. Li X, Xu S, Yu M, Wang K, Tao Y, Zhou Y, et al. Risk factors for severity and mortality in adult COVID-19 inpatients in Wuhan. J Allergy Clin Immunol. 2020;146(1):110-8.

19. Lippi G, Wong J, Henry BM. Hypertension in patients with coronavirus disease 2019 (COVID-19): a pooled analysis. Pol Arch Intern Med. 2020;130(4):304-9.

20. Zuin M, Rigatelli G, Zuliani G, Rigatelli A, Mazza A, Roncon L. Arterial hypertension and risk of death in patients with COVID-19 infection: Systematic review and meta-analysis. J Infect. 2020;81(1):e84-e86.

21. Shi S, Qin M, Shen B, Cai Y, Liu T, Yang F, et al. Association of Cardiac Injury With Mortality in Hospitalized Patients With COVID-19 in Wuhan, China. JAMA Cardiol. 2020;5(7):802-10

22. Hanff TC, Harhay MO, Brown TS, Cohen IB, Mohareb AM. Is There an Association Between COVID-19 Mortality and the Renin-Angiotensin System-a Call for Epidemiologic Investigations? Clin Infect Dis. 2020;71(15):870-4.

23. Huang I, Lim MA, Pranata R. Diabetes mellitus is associated with increased mortality and severity of disease in COVID-19 pneumonia - A systematic review, meta-analysis, and meta-regression. Diabetes Metab Syndr. 2020;14(4):395-403.

24. Henry BM, Lippi G. Chronic kidney disease is associated with severe coronavirus disease 2019 (COVID-19) infection. Int Urol Nephrol. 2020;52(6):1193-4.

25. Wang B, Li R, Lu Z, Huang Y. Does comorbidity increase the risk of patients with COVID-19: evidence from meta-analysis. Aging (Albany NY). 2020;12(7):6049-57.

26. Brown EE, Kumar S, Rajji TK, Pollock BG, Mulsant BH. Anticipating and Mitigating the Impact of the COVID-19 Pandemic on Alzheimer's Disease and Related Dementias. Am | Geriatr Psychiatry. 2020;28(7):712-21. 